which is encouraging as documentation available at point of care is likely to influence care. Only a low percentage of people were recorded as receiving palliative care. Recommendations to improve ACP uptake include: workforce education, care pathway inclusive of ACP and accessibility should be supported by national systems such as "My Health Record".

\section{OP22 CONSIDERATION AND IMPACT OF ADVANCE DIRECTIVES ON THERAPEUTIC DECISIONS IN TEN INTENSIVE CARE UNITS IN GERMAN SPEAKING SWITZERLAND}

${ }^{1} B$ Affolter*, ${ }^{2} \mathrm{~S}$ Schefold, ${ }^{2} S$ Eychmüller. ${ }^{1}$ Centre for Palliative Care, Berne, Switzerland; ${ }^{2}$ University Hospital of Berne, Berne, Switzerland

10.1136/spcare-2019-ACPICONGRESSABS.22

Background Since 2013 advance directives (AD) are binding in Switzerland. Regularly ICU doctors complain that they are not helpful for making therapeutic choices. But there is no data how often intensive care staff ask for advance directives at all and whether this represents the experience of the majority of intensive care doctors and nurses.

Methods We performed a survey in 10 Intensive Care Units (ICUs) from the German speaking part of Switzerland. The survey was sent either electronically or in paper format to 1041 professionals. Analysis was descriptive.

Results 355 (34\% response rate) professionals completed the questions concerning advance directives. Of the respondents $82 \%$ were nurses, $18 \%$ were ICU specialists or residents working in ICU. The majority of the staff asks always $(33 \%)$ or regularly $(50 \%)$ whether their patients have an AD. $6 \%$ of the doctors and $3 \%$ of the nurses say that an $\mathrm{AD}$ is always helpful for treatment decisions, while $29 \%$ of the doctors and $33 \%$ of the nurses judge it as usually helpful. $60 \%$ of doctors and $53 \%$ of nurses rated them as sometimes helpful for making therapeutic choices, while 4\% of doctors and $11 \%$ of nurses estimated ADs did not or hardly ever assisted them.

Conclusions In our survey, $83 \%$ of participants stated that they usually ask their patient or their relatives whether an $\mathrm{AD}$ exists. In contrast to the impressions from public media and personal conversations the majority of the respondents indicated that $\mathrm{ADs}$ are at least sometimes helpful for therapeutic decisions.

\section{OP23 PERCEPTIONS OF REASONS FOR DISCORDANCE BETWEEN CURRENT PREFERENCES AND EXISTING DOCUMENTATION: A QUALITATIVE STUDY}

S Hickman*, A Torke, A Myers, N Heim. Indiana University, Indianapolis, USA

\subsection{6/spcare-2019-ACPICONGRESSABS.23}

Background Nursing homes throughout the United States use the Physician Orders for Life-Sustaining Treatment (POLST) form to document resident treatment preferences as medical orders. Reasons for discordance between POLST orders and current preferences were explored in the context of a larger study of POLST discordance.

Methods Nursing facility residents $(n=25)$ and surrogate decision-makers $(n=25)$ were interviewed using Respecting
Choices Advanced Steps, a structured, advance care planning facilitation process, to elicit current values-based, informed preferences. Interviews were recorded, transcribed, and coded using qualitative descriptive methods.

Results Reasons for discordance between current preferences and POLST orders included changes in preferences related to new experiences, observations of other residents, new insights, a re-evaluation of goals and values, or a change in condition. Several participants indicated that discordance occurred because they learned new information or developed a better understanding about the treatment options during the interview. A few reported that the decisions recorded on POLST were influenced by others, though this was infrequent. Other participants were unable to explain the discordance because they did not recall the original conversation, or had no insight. Facility process issues including documentation errors and being asked to make decisions hastily during admission to the nursing facility also contributed to discordance.

Discussion Reasons for discordance are varied, but suggest a need for increased education, more frequent re-evaluation of treatment preferences, and improved practices in order to ensure nursing home documentation is concordant with the current, values-based informed preferences of residents.

\section{OP24 USAGE OF DO-NOT-ATTEMPT-TO RESUSCITATE-ORDERS IN A SWEDISH COMMUNITY HOSPITAL - PATIENT INVOLVEMENT, DOCUMENTATION AND COMPLIANCE}

1) Carlsson*, ${ }^{1} \mathrm{E}$ Bertilsson, ${ }^{2} \mathrm{~B}$ Semark, ${ }^{2} \mathrm{~K}$ Schildmeijer, ${ }^{2} \mathrm{~A}$ Bremer. ${ }^{1} \mathrm{~K} a$ lmar County Hospital, Kalmar, Sweden; ${ }^{2}$ Linnaeus University, Kalmar, Sweden

\subsection{6/spcare-2019-ACPICONGRESSABS.24}

Background The purpose of the study was to characterize patients dying in a community hospital with or without attempting cardiopulmonary resuscitation (CPR) and to describe patient involvement in, documentation of, and compliance with decisions on resuscitation (Do not attempt to resuscitate orders; DNAR).

Material and methods All patients who died in Kalmar County Hospital during January 1, 2016 until December 31, 2016 were included. All information from the patients' electronic chart was analyzed. Approved by the Regional Ethic review Board in Linköping, Sweden.

Results Of 660 patients (mean age $77.7 \pm 12.1$ years; range 21-101; median 79; 321 (48.6\%) female), a DNAR order had been documented in 563 patients (85.3\%). In 66 of 94 (70.2\%) patients without DNAR, CPR was unsuccessfully attempted. 28 of $94(29.8 \%)$ patients died without attempt at CPR and without a DNAR order in place. In 4 of 563 (0.7\%) patients CPR was attempted despite a DNAR order in place. In 416 patients $(73.9 \%)$ the DNAR order had not been discussed with neither patient nor family/friends. Moreover, in 84 cases $(14.9 \%)$ neither patient nor family/friends were even informed about the decision on code status.

Conclusions In general, a large percentage of patients in our study had a DNAR order in place (85.3\%). However, 28 patients $(4.2 \%)$ died without CPR attempt or DNAR order and DNAR orders had not been discussed with the patient/ surrogate in almost three fourths of the patients. Further work has to be done to implement ethical CPR guidelines to insure patient autonomy. 